\title{
Dimensions of trust as predictors of willingness to share and use tacit knowledge among health workers in Nigeria
}

\author{
Balogun, Anthony Gbenro $\square$ \\ Pure and Applied Psychology, Adekunle Ajasin University, Ondo State, Nigeria (tonybalogun17@yahoo.com) \\ Adetula, Gabriel Agboola \\ Pure and Applied Psychology, Adekunle Ajasin University, Ondo State, Nigeria (ade_adetula@yahoo.com)
}

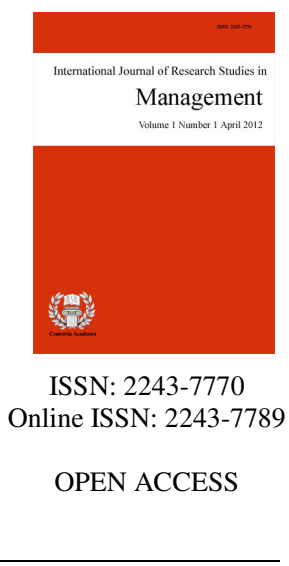

Received: 16 January 2015

Revised: 5 May 2015 DOI: $10.5861 /$ ijrsm.2015.1070

Accepted: 9 June 2015

\section{Abstract}

While there is a growing body of empirical studies on the predictors of tacit knowledge sharing behaviour among employees in service and non-service industries, little is known about health workers willingness to share and use tacit knowledge in Nigeria. This study examined how the dimensions of trust (affect-based trust and cognition-based trust) predict willingness to share and use tacit knowledge among health workers in Nigeria. The study adopted a cross-sectional survey design. Using a simple random sampling technique, a sample of 410 health workers were randomly selected from a Federal Medical Centre and a State hospital in Ondo State, South-Western Nigeria. Participants' ages ranged from 22 to 53 years with a mean of 29.61 years $(\mathrm{SD}=8.48)$. Hierarchical multiple regression analysis was used to test the study hypotheses. Results indicated that both affect-based trust and cognition-based trust significantly contributed to healthcare workers willingness to share and use tacit knowledge. However, affect-based trust contributed more than cognition-based trust to willingness to share tacit knowledge while cognition-based trust exerted more influence than affect-based trust on willingness to use tacit knowledge. Hence, we suggest that in order to facilitate tacit knowledge sharing and use among health workers, managements of healthcare sector in Nigeria should establish psychological strategies that can foster affect-based trust and cognition-based trust among health workers.

Keywords: tacit knowledge; trust; health workers; Nigeria 


\section{Dimensions of trust as predictors of willingness to share and use tacit knowledge among health workers in Nigeria}

\section{Introduction}

There is a broad recognition that tacit knowledge management is an essential source of organisation competitive advantages and innovative ideas (Leonard \& Sensiper, 1998; Hansen \& Haas, 2001). Effective management of tacit knowledge contributes to the growth and development of organisations (Ryan \& O'Connor, 2013). Tacit knowledge researchers have submitted that tacit knowledge management can enhance organisational performance, increases productivity and plays an essential role in improving quality of work, decision making, competitiveness, service delivery, and task performance (Alwis \& Hartmann, 2008; Bennett, 1998; Foos, Schum, \& Rothenburg, 2006).

Many organisations have reacted to this by spending millions of dollars annually to analyze, store, and retrieve knowledge (Lohr, 2002). However, interaction of the researchers with some medical directors in Nigeria revealed that government and managements of healthcare sector in Nigeria only invest money and effort to manage explicit knowledge or knowledge that has been made explicit via codification or writing in form of documentations, manuals, reports, data etc. instead of managing tacit knowledge. This may be due to ignorance of the fact that tacit knowledge constitutes a special category of human resources that must be uniquely managed (Olapegba, Balogun, \& Idemudia, 2013).

The availability and use of tacit knowledge in organisations depends on employees' willingness to share their tacit knowledge within the organisation. This is because tacit knowledge only resides in the minds and heads of individual employees (Fahey \& Prusak, 1998; Nonaka \& Takeuchi, 1995; Polanyi, 1966). But unfortunately, the researchers in-depth interactions with some health workers in Nigeria revealed that most health workers are always reluctant to share and use tacit knowledge within the organisation because of the risks involve (e.g. losing competitive edge and status to co-workers, getting incomplete knowledge from a knowledge source and poor results after applying the knowledge). Hence, it becomes imperative to examine the factors that can predict tacit knowledge sharing and use among health workers in Nigeria.

Although studies (e.g., Foos et al., 2006; Holste \& Fields, 2010; Li, Zhu, \& Wang, 2010; Ryan et al., 2013; Yazdani \& Siddique, 2013) have examined how interpersonal trust, altruism, need satisfaction, social support, early involvement, due diligence, and culture predict tacit knowledge sharing and use among employees in service and non-service organisations such as technology/software companies, business firms, and missionary organisations, little is known about the predictors of health workers willingness to share and use tacit knowledge in general and Nigeria in particular.

In the few extant research that do considered the predictors of tacit knowledge sharing behaviour among health workers in Nigeria, their focus tend to be on how personality characteristics (e.g. altruism and self-efficacy) and demographic variables such as age, gender, job tenure, and level of education connect with health workers willingness to "share" tacit knowledge (Balogun, 2014a; Balogun, 2014b). However, none of these studies consider the influence of contextual factors such as affect-based trust and cognition-based trust (dimensions of trust) on willingness to share and use tacit knowledge amongst health workers. Hence, a gap exists in literature. In response to this gap, the present study investigated the influence of affect-based and cognition-based trusts on willingness to share and use tacit knowledge amongst health workers in Nigeria. Evidence from this study would provide insight on how affect-based and cognition-based trusts can be foster to facilitate tacit knowledge sharing and use among health workers. 


\subsection{What is Tacit Knowledge?}

Tacit knowledge, an antithesis of explicit knowledge, is a knowledge that resides only in individual employee's mind and head in forms of know-how, ideas, skills, values, intuition, schemata, and mental models (Fahey et al., 1998; Cross \& Baird, 2000; Polanyi, 1966). Nonaka et al. (1995) described tacit knowledge as a "non-linguistic, non-numerical form of knowledge that is highly personal and context specific and deeply rooted in individual experiences, ideas, values and emotions". They distinguish between "technical tacit knowledge" (meaning skills or concrete 'know-how), and "cognitive tacit knowledge" which refers to imagined schema, beliefs and mental models that are taken for granted. Tacit knowledge is an individual personal and internal knowledge as opposed to the external, physical knowledge that has been written down or recorded as an artifact (explicit knowledge).

Gourlay (2002) conceptualised tacit knowledge as a type of knowledge that is highly personal and context specific and deeply rooted in individual experiences, ideas, values and emotion. Tacit knowledge is often the product of experience (Duffy, 2000). This may explain why a veteran family planning provider who has counseled thousands of clients performs better than does a less experienced counterpart following a written protocol (Bolarinwa, Salaudeen, \& Akande, 2012). Explicit knowledge on the other hand, is a knowledge which can be codified into words, numbers, codes databases etc and is transferred in formal and systemic way (Nonaka, 1994). Procedural manuals, product manuals, computer software, mathematical formulas, patents, and codes are examples of explicit knowledge (Nonaka \& Takeuchi, 1995).

Tacit knowledge researchers have submitted that tacit knowledge is difficult (if not impossible) to reduce to writing like explicit knowledge (Polanyi, 1966; Nonaka, Totama, \& Nagata, 2000; Koskinen, 2003). This is because individuals with tacit knowledge cannot express it in a way that can be written down (Alwis et al., 2008; Lai, 2005). If expressed at all, it takes the form of analogies, stories, and metaphor (Blumentritt \& Johnston, 1999; Choo, 1998; Nonaka et al., 1995).

\section{Literature Review and Hypotheses}

Tacit knowledge requires interpersonal and face-to-face interaction for its sharing and use (Grover \& Davenport, 2001; Nonaka, 1994; Scott, 2000). The sharing and use of tacit knowledge depends on the extent that co-workers trusted each other (Lucas, 2005; O'Neill \& Adya, 2007). When there is no interpersonal trust, employees do not share knowledge despite any formal requirements for sharing knowledge (Andrews \& Delahaye, 2000). Therefore, there is a need of an element of interpersonal trust between the employees to help them share and use their knowledge among themselves.

Trust is a "psychological state comprising the intention to accept vulnerability based upon positive expectations of the intentions or behaviour of another" (Rousseau, Sitkin, Burt, \& Camerer, 1998, p. 395). It is widely acknowledged that trust arises through distinct psychological processes (Lewicki \& Bunker, 1996; Lewis \& Weigert, 1985; McAllister, 1995). A central distinction is that between affect- versus cognition-based trusts (McAllister, 1995). Affect-based trust is grounded in relationships where the parties have strong emotional tie, reciprocal care and concern, and mutual relationship between employees (McAllister, 1995). With affect-based trust, individuals express care and concern for the welfare of their partners and believe in the intrinsic virtue of such relationships (Rempel, Holmes, \& Zanna, 1985).

Cognition-based trust on the other hand describes a relationship in which an individual believes that another person is knowledgeable about a given area. It is a judgment based on evidence of another's competence and reliability. McAllister (1995) argued that cognition-based trust exists when one is being trusted because of his/her cognitive abilities, competencies, reliability and dependability, experience and quality of work. For example, when we trust someone because of his superior knowledge and experience in the field we have cognition-based trust. While affect-based trust encourages social relationships, cognition-based trust promotes 
professional association among the employees (Chowdhury, 2005).

Research has shown that willingness to share and use tacit knowledge among organisational members requires intimate personal relationship (Epstein, 2000; Nonaka et al., 1995). Most employees develop intimate personal relationship with other employees through frequent and face-to-face interactions; through this, they develop affect-based trust and cognition-based trust (Yazdani et al., 2013). Past studies revealed that both affect-based trust and cognition-based trust must be present for employees to be willing to share and use tacit knowledge (Chowdhury, 2005). For example, Lucas (2005) found that interpersonal trust (similar to affect-based trust) and reputation of knowledge source and recipient (similar to cognition-based trust) contributed significantly to knowledge sharing. In a study conducted in United State, Holste et al. (2010) found that missionaries' willingness to share and use tacit knowledge was facilitated by both affect-based trust and cognition-based trust. In Pakistan, Yazdani et al. (2013) reported that affect-based and cognition-based trusts positively predicted employees' willingness to share and use tacit knowledge. Thus, it was hypothesized that:

Hypothesis 1: Both affect-based trust and cognition-based trust will significantly predict health workers willingness to share and use tacit knowledge.

Sharing tacit knowledge may involve risks to an employee (a knowledge source), such as loss of competitive advantage to/over peers (Stenmark, 2002). Thus, this study argued that affect-based trust may have a larger influence than cognition-based trust on employee's willingness to share tacit knowledge. The findings of Holste et al. (2010) attested to this. The authors found that affect-based trust increased missionaries' willingness to share tacit knowledge than cognition-based trust. Several studies (e.g. Epstein, 2000) have shown that individuals with intimate personal relationship (an affect-based trust) are more likely to exchange personal knowledge through face-to-face communications. For example, Hansen (1999) found that strong personal ties facilitated tacit knowledge exchange between work units. Nonaka et al. (1995) also reported that tacit knowledge sharing increased more among co-workers with intimate personal relationships. Foos, Schum, and Rothenburg (2006) found a significant positive connection between interpersonal trust and tacit knowledge transfer among project team members. These previous studies highlighted the importance of affect-based trust in employee's willingness to share tacit knowledge. Therefore, it would not be out of place to argue that affect-based trust will contribute more than cognition-based trust to healthcare workers willingness to share tacit knowledge. It was therefore, hypothesized that:

Hypothesis 2: Affect-based trust will have a larger influence than cognition-based trust on health workers willingness to share tacit knowledge.

The use of others tacit knowledge may also involve risks to an employee (a knowledge recipient), such as a knowledge source providing incomplete knowledge or getting poor result after applying the knowledge (Holste et al., 2010). Therefore, for an employee to use others tacit knowledge, he/she must perceive that the knowledge is from an employee who is reliable and dependable, has good reputation within organisation, and perceive that there are benefits from using the knowledge. Thus, cognition-based trust may contribute more than affect-based trust to employees' willingness to use tacit knowledge.

Previous studies (e.g., Perloff, 1993; Yazdani et al., 2013) reported a significant positive relationship between cognition-based trust and use of tacit knowledge, such that employees' use of tacit knowledge increased with cognition-based trust. Indeed, people may accept knowledge from individuals whom they perceived as trustworthy, reliable, and dependable (Szulanski, 1995). The finding of Lucas (2005) revealed that use of co-workers' knowledge increased when recipients perceived the knowledge source as one who has a good reputation in the organisation. Holste et al. (2010) also reported that the perceived competence and professionalism (i.e. cognition-based trust) knowledge source is a more critical determinant of willingness to use such knowledge. Therefore, willingness to use tacit knowledge may be strongly based on an employee's understanding of the accuracy and validity of the knowledge and reputation of the source (Choo, 1998; Szulanski, 1995, 1996). Hence, it was hypothesized that: 
Hypothesis 3: Cognition-based trust will have a larger influence than affect-based trust on health workers willingness to use tacit knowledge.

\section{Method}

\subsection{Research Design}

This study adopted a cross-sectional survey design. This is appropriate because the objective of the study was predictive and data was collected at a single point in time. The independent variables are affect-based trust and cognition-based trust and the dependent variables are willingness to share and use tacit knowledge.

\subsection{Participants}

Using a simple random sampling technique, four hundred and ten $(410)$ health workers (nurses $=281$; doctors $=129$ ) were selected from two public hospitals in a south-west state (Ondo State) in Nigeria. The participants' comprised of 198 (48.3\%) males and 212 (51.7\%) females. Their ages ranged from 22 to 53 years with a mean of 29.61 years and standard deviation of 8.48. Also, $229(55.9 \%)$ of the participants were married, $181(44.1 \%)$ were single. In terms of job status, 241 (58.8\%) employees were in junior cadre, $169(41.2 \%)$ were in senior cadre. Most of the participants had organisational tenure of over 3 years. Regarding their religion affiliation, 214 (52.2\%) were Muslims while 196 (47.8\%) were Christians.

\subsection{Instrument}

A biographical questionnaire was administered in order to document the socio-demographical characteristics of the participants. Questions covered age, gender, and job tenure.

Willingness to Share and Use Tacit knowledge: These were assessed with an 8-item scale developed by Holste et al. (2010). The first 4-item measures willingness to share tacit knowledge while the remaining 4-item assessed employees' willingness to use tacit knowledge. Sample items include: "I would willingly share my new ideas with this individual" (willingness to share knowledge) and "I would eagerly receive and consider any new ideas this individual might have" (willingness to use tacit knowledge). The items are rated on seven-point Likert scale ranging from $1=$ strongly disagree to $7=$ strongly agree. Holste et al. (2010) reported a Cronbach's alpha of 0.85 for items measuring willingness to share tacit knowledge while 0.84 was obtained for items measuring willingness to use tacit knowledge. The construct validity coefficients for the two sub-scales were 0.69 and 0.78 respectively (Holste et al., 2010). In the present study, a Cronbach's alpha of 0.61 (willingness to share tacit knowledge) and 0.81 (willingness to use tacit knowledge) were obtained respectively. Scores above the mean implies high willingness to share and use tacit knowledge while score below the mean implies low willingness to share and use tacit knowledge.

Affect-based and Cognition-based Trusts: These were measured using 11-item interpersonal trust scale developed by McAllister (1995). The scale assessed two dimensions of interpersonal trust. 5-item of the scale, which had a Cronbach's alpha of 0.93 measures affect-based trust. Sample item include "I would have to say that we have made considerable emotional involvement in our working relationship". Cognition-based trust on the other hand was tapped using McAllister (1995) 6-item survey. Sample item include "I can rely on this person not to make my job more difficult through careless work". McAllister (1995) reported a Cronbach's alpha of 0.93 for the 6-item sub-scale. In the present study, Cronbach's alpha of 0.81 and 0.72 were obtained for the two sub-scales respectively while a Cronbach's alpha of 0.70 was obtained for the overall scale. Scores above or equal the mean implies high level of affect-based and cognition-based trusts. 


\subsection{Procedure}

The participants for this study were drawn from two public hospitals (a Federal Medical Centre and a State General Hospital) in Ondo State, Nigeria. The researchers sought and obtained permission from the Chief Medical Director (CMD) and Head of Nursing Services of the hospital after the purpose of the study had been clearly explained to them. Using a list of medical doctors and nursing staff at the hospitals, participants were selected using a simple random sampling technique (odd and even numbers). Only employees with even numbers were selected. The purpose of the study was explained to the participants. They were informed that participation was purely voluntary and that they were free to discontinue whenever they felt uncomfortable to continue with the research. The participants were also given assurance of confidentiality and anonymity of their identities and responses. Four hundred and fifty (450) questionnaires were distributed to participants that consented. Four hundred forty one (441) of these questionnaires were retrieved out of which four hundred and ten (410) were duly completed and found usable for the analysis.

\section{Results}

Descriptive and Correlational analyses were performed on the data. The results are presented in Table 1.

\section{Table 1}

Mean, Standard Deviation, and Correlations among Study Variables

\begin{tabular}{llllllll}
\hline Variables & 1 & 2 & 3 & 4 & 5 & 6 & 7 \\
\hline 1 Age & 1 & & & & & & \\
2 Gender & $.60^{* *}$ & 1 & & & & & \\
3 Job tenure & $.75^{* *}$ & $-.11^{*}$ & 1 & & & & \\
4 Affect-based trust & $.28^{*}$ & -03 & $-.11^{*}$ & 1 & & & \\
5 Cognition-based trust & $.13^{*}$ & $.51^{* *}$ & $-.37^{*}$ & $.38^{* *}$ & 1 & & \\
6 Willingness to share TK & .03 & -.09 & .06 & $.22^{* *}$ & $.29^{*}$ & 1 & \\
7 Willingness to use TK & .02 & .09 & .08 & $.18^{*}$ & $.23 *$ & $.11^{* *}$ & 1 \\
Mean & 41.6 & - & 12.8 & 5.32 & 6.14 & 5.32 & 5.37 \\
SD & 9.23 & - & 7.45 & 2.58 & 3.79 & 1.64 & 1.91 \\
\hline Note. ${ }^{*} p .05$ level (2-tailed); ** $p .01$ level (2-tailed). TK = Tacit Knowledge & & & &
\end{tabular}

Results in Table 1 indicated that affect-based trust had a significant positive relationship with willingness to share $(\mathrm{r}=.22, p<.01)$ and use $(\mathrm{r}=.18, p<.05)$ tacit knowledge. This implies that health workers willingness to share and use tacit knowledge increased with high level of affect-based trust. Moreover, cognition-based trust had a significant positive relationship with willingness to share $(\mathrm{r}=.29, p<.05)$ and use $(\mathrm{r}=.23, p<.05)$ tacit knowledge. This suggests that as cognition-based trust increases between health workers, their willingness to share and use tacit knowledge also increases.

Two models hierarchical multiple regression analyses were conducted to test the study hypotheses. Control variables: age, gender, and job tenure were entered at model 1 while affect-based and cognition-based trusts were added at model 2 . The results are presented in Table 2 .

Results in model 1 of the equations showed that the control variables made no significant joint contribution to explain variance in willingness to share $\left(\mathrm{R}^{2}=.01, \mathrm{~F}(3,407)=0.38, p>.05\right)$ and use $\left(\mathrm{R}^{2}=.03, \mathrm{~F}(3,407)=\right.$ $0.71, p>.05)$ tacit knowledge. Moreover, the relative predictive value of each variable showed that none of the control variables significantly predicted willingness to share and use tacit knowledge. These imply that health workers would be willing to share and use tacit knowledge irrespective of their age, gender, and job tenure.

However, the results in model 2 provided evidence in support of hypothesis 1 . The inclusion of affect-based trust and cognition-based trust in model 2, accounted for 52\% variance in health workers willingness to share tacit knowledge $\left(\mathrm{R}^{2}=.52, \mathrm{~F}=42.18, p<.01\right)$ and $46 \%$ variance in healthcare workers willingness to use tacit knowledge $\left(\mathrm{R}^{2}=.46, \mathrm{~F}=31.20, p<.05\right)$. The two dimensions of trust alone accounted for $51 \%(\Delta \mathrm{R}=.51)$ and 
Dimensions of trust as predictors of willingness to share and use tacit knowledge among health workers

$43 \%(\Delta \mathrm{R}=.43)$ variance in willingness to share and use tacit knowledge respectively. These imply that both affect-based and cognition-based trusts are significant predictors of health workers willingness to share and use tacit knowledge. Hence, hypothesis 1 was confirmed.

Table 2

Hierarchical Multiple Regression on Dimensions of Trust and Willingness to Share and Use Tacit Knowledge

\begin{tabular}{|c|c|c|}
\hline \multicolumn{2}{|c|}{$\begin{array}{l}\text { Willingness to Share } \\
\text { Tacit Knowledge }\end{array}$} & $\begin{array}{l}\text { Willingness to Use } \\
\text { Tacit Knowledge }\end{array}$ \\
\hline Variables & $\beta$ & $\beta$ \\
\hline \multicolumn{3}{|l|}{ Model 1} \\
\hline Age & .03 & .02 \\
\hline Gender & -.09 & .09 \\
\hline Job tenure & .06 & .08 \\
\hline$R$ & .04 & .02 \\
\hline$R^{2}$ & .01 & .03 \\
\hline$F$-ratio & 0.38 & 0.71 \\
\hline \multicolumn{3}{|l|}{ Model 2} \\
\hline Age & .03 & .02 \\
\hline Gender & -.09 & .09 \\
\hline Job tenure & .06 & .08 \\
\hline Affect-based trust & $.52 * *$ & $.19 *$ \\
\hline Cognition-based trust & $.29 *$ & $.33 *$ \\
\hline$R$ & .46 & .27 \\
\hline$R^{2}$ & .52 & .46 \\
\hline$\Delta R$ & .51 & .43 \\
\hline$F$-ratio & $42.18 * *$ & $31.20 *$ \\
\hline
\end{tabular}

Note. ${ }^{*} p<0.05, * * p<0.01, \mathrm{~N}=410$

Affect-based trust significantly predicted health workers willingness to share $(\beta=.52, p<.01)$ and use $(\beta$ $=.19, p<.05)$ tacit knowledge. This implies that health workers with affect-based trust reported higher willingness to share and use tacit knowledge. However, the beta coefficient showed that affect-based trust ( $\beta$ $=.52)$ had a larger influence than cognitive-based trust $(\beta=.29)$ on willingness to share tacit knowledge. Thus, hypothesis 2 was confirmed.

Cognition-based trust also significantly predicted willingness to share $(\beta=.29, p<.05)$ and use $(\beta=.33, p$ $<.05)$ tacit knowledge, suggesting that health workers with cognitive-based trust reported higher willingness to share and use tacit knowledge. However, the coefficient showed that cognition-based trust $(\beta=.33)$ had a greater influence than affect-based trust $(\beta=.19)$ on health workers willingness to use tacit knowledge. Hence, hypothesis 3 was supported.

\section{Discussion}

The aim of this study was to investigate the extent to which affect-based trust and cognition-based trust predict willingness to share and use tacit knowledge amongst health workers in Nigeria. Findings show that both affect-based trust and cognition-based trust significantly predicted health workers willingness to share tacit knowledge. However, affect-based trust had a larger influence than cognition-based trust on willingness to share tacit knowledge. This implies that willingness to share tacit knowledge increased more with affect-based trust. This finding support the research of Holste et al. (2010) and Yazdani et al. (2013) who found that affect-based trust significantly contributed more than cognition-based trust to tacit knowledge sharing and use. This result is also in tandem with Nonaka et al. (1995) findings which revealed that tacit knowledge sharing increased more among co-workers with intimate personal relationships.

This finding is not surprising because sharing tacit knowledge may involve risks to a knowledge source, such as loss of competitive advantage over peers (Stenmark, 2002). Hence, a health workers would prefer to share his/her tacit knowledge with co-workers whom he/she strongly trust (affect-based trust) and whom he/she 
also perceive will professionally use the knowledge (cognition-based trust).

In support of previous findings (e.g. Holste, et al. 2010), both affect-based trust and cognition-based trust significantly predicted health workers willingness to use tacit knowledge. However, cognition-based trust contributed more than affect-based trust to willingness to use tacit knowledge of health workers. These findings support the findings of Holste et al. (2010) and Yazdani et al. (2013) who reported that cognition-based trust exerted more influence than affect-based trust on willingness to use tacit knowledge. A possible explanation is that the use of co-workers tacit knowledge may involve risk to a knowledge recipient. For instance, if a health worker uses a co-worker tacit knowledge and applies it but gets poor results, he/she will be less likely to use knowledge from the co-worker because of the fear of getting poor result. Hence, the use tacit knowledge is strongly based on an employee's understanding of the accuracy and validity of the knowledge and reputation of the source (Choo, 1998; Szulanski, 1995, 1996).

Previous studies (e.g., Lucas, 2005; Perloff, 1993; Szulanski, 1995) have shown that the use of co-workers' knowledge increased when recipient perceived the knowledge source as one who is reliable, dependable, trustworthy, and has a good reputation in the organisation. However, while cognition-based trust has substantial influence on the willingness to use tacit knowledge, affect-based trust must also be present (Holste et al. 2010). For example, if an individual is capable and competent to use tacit knowledge but does not have intimate relationship (affect-based trust) with other co-workers, such employees will not be able to acquire tacit knowledge from his/her colleagues (Yazdani et al., 2013). So, both dimensions of trust are important in the use of tacit knowledge.

\section{Conclusion}

Based on the findings of this study, it was concluded that affect-based trust and cognition-based trust are important predictors of health workers willingness to share and use tacit knowledge in Nigeria. Hence, we recommended that to facilitate knowledge sharing and use among health workers, management of healthcare sector in Nigeria should established psychological strategies that can foster affect-based trust and cognition-based trust among health workers. Despite the contributions of this study, some limitations were recognized. For instance, it is possible that workers working in private organisations might weigh affect-based and cognition-based trusts differently in making decisions to share and use tacit knowledge. Unfortunately, employees in private organisation were not captured in this study. A sample that reflects national spread may ensure the generalization of the present findings. Moreover, the cross-sectional nature of the data calls into question any inferences that could be made concerning the directionality of relationships.

\section{References}

Alony, I., Whymark, G., \& Jones, M. (2007). Sharing tacit knowledge: a case study in the Australian film industry. Informing Science Journal, 10, 41-59.

Alwis, R. S., \& Hartmann, E. (2008).The use of tacit knowledge within innovative companies: knowledge management in innovative enterprises. Journal of Knowledge Management, 12(1), 133-147. http://dx.doi.org/10.1108/13673270810852449

Andrews, K. M., \& Delahaye, B. L. (2000). Influences on knowledge processes in organizational learning: The psychosocial filter. Journal of Management Studies, 37(6), 797-810. http://dx.doi.org/10.1111/1467-6486.00204

Balogun, A. G. (2014a). Demographic variables predicting employees' willingness to share tacit knowledge in service occupations. Ife PsychologIA, 22(2), 44-49.

Balogun, A. G. (2014b). Personal characteristics and willingness to share tacit knowledge: Is there a connection? Nigerian Journal of Applied Behavioural Science, 2, 104-114.

Bennett, R. H. (1998). The importance of tacit knowledge in strategic deliberations and decisions. Management Decision, 36(9), 97-589. http://dx.doi.org/10.1108/00251749810239478

Blumentritt, R., \& Johnston, R. (1999). Towards a strategy for knowledge management. Technology Analysis and 
Dimensions of trust as predictors of willingness to share and use tacit knowledge among health workers

Strategic Management Issues, 10(2), 22-204. http://dx.doi.org/10.1080/095373299107366

Bolarinwa, O. A., Salaudeen, A. G., \& Akande, T. M. (2012). Overview of knowledge management applications in health care delivery of developing countries. Academic Research International, 3(3), 38-45.

Burke, J. (2001). Towards a new classification of non-experimental qualitative research. Educational Researcher, 30(2), 3-13. http://dx.doi.org/10.3102/0013189X030002003

Choo, C. W. (1998). The knowing organisation: How organisations use information to construct meaning, create knowledge and make decision. Oxford University Press, New York, NY.

Chowdhury, S. (2005). The role of affect-based and cognitive-based trusts in complex knowledge sharing. Journal of Management Issues, 17(3), 310-326.

Cross, R., \& Baird, L. (2000). Technology is not enough improving performance by building organisational memory. Sloan Management Review, 41(3), 69-78.

Duffy, J. (2000). Knowledge management: To be or not to be? Information Management Journal, 34(1), 7-64.

Epstein, L. D. (2000). Sharing knowledge in organizations: how people use media to communicate. Unpublished dissertation, University of California, Berkeley, CA.

Fahey, L., \& Prusak, L. (1998).The 11 deadliest sins of knowledge management. California International Journal, 35(10), 1427-1436.

Foos, T., Schum, G., \& Rothenburg, S. (2006). Tacit knowledge transfer and the knowledge disconnect. Journal of Knowledge Management, 10(1), 6-18. http://dx.doi.org/10.1108/13673270610650067

Fukuyama, F. (1995). Trust: The social virtues and the creation of prosperity. New York, NY: The Free Press.

Gourlay, S. (2002). Tacit knowledge, tacit knowing or behaving? 3rd European Organizational Knowledge, Learning and Capabilities Conference, Athens, Greece, 5-6 April.

Grover, V., \& Davenport, T. H. (2001). General perspectives on knowledge management: Fostering a research agenda. Journal of management information systems, 18(1), 5-22.

Hansen, M. T., \& Haas, M. R. (2001). Different knowledge, different benefits, toward a productivity perspective on knowledge sharing in organizations. Academy of Management Proceedings. http://dx.doi.org/10.5465/APBPP.2001.27442901

Hansen, M. T. (1999). The search-transfer problem: the role of weak ties in sharing knowledge across organisation subunits. Administrative Science Quarterly, 44(1), 82-111. http://dx.doi.org/10.2307/2667032

Holste, J. S., \& Fields, D. (2010). Trust and tacit knowledge sharing and use. Journal of knowledge Management, 14(1), 128-140. http://dx.doi.org/10.1108/13673271011015615

Koskinen, K. U. (2003). Evaluation of tacit knowledge utilization in work units, Journal of knowledge management, 7(5), 67-81. http://dx.doi.org/10.1108/13673270310505395

Lai, I. L. A. (2005). Knowledge management for Chinese medicines: a conceptual model. Information Management \& Computer Security, 13, 244-255. http://dx.doi.org/10.1108/09685220510602059

Leonard, D., \& Sensiper, S. (1998). The role of tacit knowledge in group innovations. California Management Review, 40(3), 113-132. http://dx.doi.org/10.2307/41165946

Lewicki, R. J., \& Bunker, B. B. (1996). Developing and maintaining trust in work relationships. In R. M. Kramer \& T. R. Tyler (Eds.), Trust in organizations: Frontiers of theory and research (pp. 114-139). Thousand Oaks, CA: Sage. http://dx.doi.org/10.4135/9781452243610.n7

Lewis, J. D., \& Weigert, A. (1985). Trust as a social reality. Social Forces, 63, 967-985. http://dx.doi.org/10.1093/sf/63.4.967

Li, Z., Zhu, T., \& Wang, H. (2010). A study on the influence factors of the intention to share tacit knowledge in the university research team. Journal of Software, 5(5), 538-545.

Lohr, S. (2002). Gasing into 2003: economy intrudes on dreams of new service. The New York Times, December $30, \mathrm{p} 3$.

Lucas, L. (2005). The impact of trust and reputation on the transfer of best practices. Journal of Knowledge Management, 9(4), 87-101. http://dx.doi.org/10.1108/13673270510610350

McAllister, D. J. (1995).Affect-and cognition-based trusts as foundations for interpersonal cooperation in organizations. Academy of Management Journal, 38(1), 24-59. http://dx.doi.org/10.2307/256727 
Balogun, A. G., \& Adetula, G. A.

Nonaka, I., \& Konno, N. (1998). The creation of building a foundation for knowledge sharing. Creation California Management Review, 43(3), 40-54. http://dx.doi.org/10.2307/41165942

Nonaka, I., \& Takeuchi, H. (1995). The knowledge creating company. New York, NY: Oxford University Press.

Nonaka, I. (1994). A dynamic theory of organizational knowledge creation. Organization Science, 5(1), 14-37. http://dx.doi.org/10.1287/orsc.5.1.14

Nonaka, I., Totama, R., \& Nagata, A. (2000). A firm as a knowledge-creating entity: A new perspective on the theory of the firm, Industrial and Corporate Change, 9(1), 1-20. http://dx.doi.org/10.1093/icc/9.1.1

O'Neill, B. S., \& Adya, M. (2007). Knowledge sharing and the psychological contract: Managing knowledge workers across different stages of employment. Journal of Managerial Psychology, 22(4), 411-436. http://dx.doi.org/10.1108/02683940710745969

Perloff, R. M. (1993). The dynamics of persuasion. Hillsdale, NJ: Lawrence Erlbaum Association.

Polanyi, M. (1966). The tacit dimension. New York, NY.: Doubleday Anchor.

Rempel, J. K., Holmes, J. G., \& Zanna, M. D. (1985). Trust in close relationships. Journal of Personality and Social Psychology, 49, 95-112. http://dx.doi.org/10.1037/0022-3514.49.1.95

Ryan, S., \& O'Connor, R. (2013). Acquiring and sharing tacit knowledge in software development teams: An empirical study. Information and Software Technology, 55(9), 1614-1624. http://dx.doi.org/10.1016/j.infsof.2013.02.013

Scott, J. (2000). Facilitating inter-organisational learning with information technology. Journal of Management Information Systems, 17(2), 81-113.

Selamat, M. H., \& Choudrie, J. (2004). The diffusion of tacit knowledge and its implications on information systems: The role of meta-abilities. Journal of Knowledge Management, 8, 128-139. http://dx.doi.org/10.1108/13673270410529163

Stenmark, D. (2002). Sharing tacit knowledge: A case study at Volvo. In S. Barnes (Ed.), Knowledge management system: Theory and practice (pp. 36-48). Thomson Learning, London.

Szulanski, G. (1995). Unpacking stickness: An empirical investigation of the barriers to transfer best practice in the firm. Academy of Management Journal, 38, 437-441.

Szulanski, G. (1996). Exploring internal stickiness: impediments to the transfer of best practice within the firm. Strategic Management Journal, 17, 27-43. http://dx.doi.org/10.1002/smj.4250171105

Yazdani, N., \& Siddique, A. (2013). The effect of affect-based and cognitive-based trusts on the sharing and use of tacit knowledge. Paper presented at University of Management and Technology, Lahore, Pakistan between 27-28 of February, 2013. 